\title{
Advance care planning for patients with chronic respiratory diseases: a systematic review of preferences and practices
}

\author{
Lea J Jabbarian, ${ }^{1}$ Marieke Zwakman, ${ }^{2}$ Agnes van der Heide, ${ }^{1}$ Marijke C Kars, ${ }^{2}$ \\ Daisy J A Janssen, ${ }^{3,4}$ Johannes J van Delden, ${ }^{2}$ Judith A C Rietjens, ${ }^{1}$ Ida J Korfage ${ }^{1}$
}

\begin{abstract}
- Additional material is published online only. To view please visit the journal online (http://dx.doi.org/10.1136/ thoraxjnl-2016-209806).

${ }^{1}$ Department of Public Health, Erasmus University Medical Centre, Rotterdam, The Netherlands

${ }^{2}$ Julius Center for Health Sciences and Primary Care University Medical Center, Utrecht, The Netherlands ${ }^{3}$ Department of Research and Education, Centre of Expertise for Chronic Organ Failure (CIRO), Horn, The Netherlands ${ }^{4}$ Centre of Expertise for Palliative Care, Maastricht University Medical Centre (MUMC+), Maastricht, The Netherlands
\end{abstract}

Correspondence to Lea J Jabbarian, Department of Public Health, Erasmus University Medical Centre, 3000 CA, Rotterdam, The Netherlands; l.jabbarian@ erasmusmc.n

JACR and IJK contributed equally.

Preliminary results have been presented at the 37th Annual North American Meeting of the Society for Medical Decision Making and at the 9th World Research Congress of the European Association for Palliative Care

Received 9 December 2016 Revised 22 August 2017 Accepted 18 September 2017 Published Online First 6 November 2017

Check for updates

To cite: Jabbarian $L J$,

Zwakman M, van der

Heide A, et al. Thorax

2018:73:222-230.
ABSTRACT
Background Advance care planning (ACP) supports patients in identifying and documenting their preferences and timely discussing them with their relatives and healthcare professionals (HCPs). Since the British Thoracic Society encourages ACP in chronic respiratory disease, the objective was to systematically review ACP practice in chronic respiratory disease, attitudes of patients and HCPs and barriers and facilitators related to engagement in ACP.

Methods We systematically searched 12 electronic databases for empirical studies on ACP in adults with chronic respiratory diseases. Identified studies underwent full review and data extraction.

Results Of 2509 studies, 21 were eligible: 10 were quantitative studies. Although a majority of patients was interested in engaging in ACP, ACP was rarely carried out. Many HCPs acknowledged the importance of ACP but were hesitant to initiate it. Barriers to engagement in ACP were the complex disease course of patients with chronic respiratory diseases, HCPs' concern of taking away patients' hopes and lack of continuity of care. The identification of trigger points and training of HCPs on how to communicate sensitive topics were identified as facilitators to engagement in ACP.

Conclusions In conclusion, ACP is surprisingly uncommon in chronic respiratory disease, possibly due to the complex disease course of chronic respiratory diseases and ambivalence of both patients and HCPs to engage in ACP. Providing patients with information about their disease can help meeting their needs. Additionally, support of HCPs through identification of trigger points, training and system-related changes can facilitate engagement in ACP.

Systematic review registration number CRD42016039787.

\section{INTRODUCTION}

Chronic respiratory diseases have grown in prevalence and are major causes of health burden and death. ${ }^{1}{ }^{2}$ Chronic obstructive pulmonary disease (COPD), for example, has become the fourth leading cause of death worldwide. ${ }^{3}$ Patients with chronic respiratory diseases, such as COPD or pulmonary fibrosis, experience a complex and often unpredictable disease course, ${ }^{4}$ which is characterised by a gradual decline, interrupted by sudden and life-threatening exacerbations. ${ }^{5}$ As the disease progresses, complications may become

\section{Key messages}

What is the key question?

- What is the current practice of advance care planning (ACP) for patients with chronic respiratory diseases?

What is the bottom line?

- Based on the literature, we outlined the current practice of ACP in chronic respiratory disease, identified barriers preventing and facilitators enabling engagement in ACP and formulated recommendations on how to overcome barriers related to patients, HCPs and the healthcare system.

\section{Why read on?}

- ACP is surprisingly uncommon in chronic respiratory disease, possibly due to the complex disease course of chronic respiratory diseases and ambivalence of both patients and healthcare professionals (HCPs) to engage in ACP.

more frequent and complex. ${ }^{7}$ Disease progression may also lead to a variety of symptoms, such as dyspnoea, and comorbidities, which can reduce the quality of life of patients substantially. ${ }^{7}$ Patients, their relatives and healthcare professionals (HCPs) are faced with treatment decisions throughout the disease course. Acute deterioration of health can, ${ }^{7}$ for instance, result in respiratory failure requiring mechanical ventilation and the necessity of having to make ad hoc decisions on how to proceed. ${ }^{8}$

Since patient preferences for treatments such as mechanical ventilation vary, ${ }^{9}$ patient-centred discussions about goals of care are needed, while taking into account patients' preferences for content and timing of such discussions. ${ }^{10}$ The British Thoracic Society and American College of Chest Physicians acknowledge advance care planning (ACP) as an integral part of cardiopulmonary medicine and encourage end-of-life discussions about goals of care. ${ }^{11} 12$ ACP is a means to support patients in identifying their preferences of care, discussing these preferences timely with their relatives and HCPs and, if desired, documenting them in an advance directive (AD). In other disease groups, such as frail nursing home residents, ACP has been 
found to have beneficial effects on the communication between patients and HCPs and patients' quality of life. ${ }^{13}$ ACP has also been found to have the potential to increase patients' satisfaction with care and care being delivered in accordance with patients' preferences. ${ }^{13}$

To date, there is no thorough overview of the use of ACP for patients with chronic respiratory diseases, of the attitudes towards ACP of those who may be involved in it and of comprehensive ACP programmes in this context. This systematic review aims to describe ACP practice in chronic respiratory disease, summarising findings on (1) how ACP is defined in chronic respiratory disease, (2) the experiences with and attitudes towards ACP of patients and HCPs, (3) the barriers and facilitators related to engagement in ACP and (4) the effects of ACP programmes.

\section{METHODS}

\section{Registration of the review}

This systematic review was registered at the PROSPERO register (registration number: CRD42016039787). The full form can be accessed online at https://www.crd.york.ac.uk/PROSPERO/

\section{Inclusion and exclusion criteria}

We conceptualised ACP following the comprehensive definition of the National Academy of Medicine (NAM):

\begin{abstract}
Advance care planning refers to the whole process of discussion of end-of-life care, clarification of related values and goals, and embodiment of preferences through written documents and medical orders. This process can start at any time and be revisited periodically, but it becomes more focused as health status changes. Ideally, these conversations (1) occur with a person's healthcare agent and primary clinician, along with other members of the clinical team; (2) are recorded and updated as needed; and (3) allow for flexible decision making in the context of the patient's current medical situation. ${ }^{14}$
\end{abstract}

Based on this definition, we identified four core elements of ACP (see box).

We included studies with interventions, programmes or activities that were labelled as 'advanced care planning' by the authors or studies addressing one or more core elements of ACP as defined by the NAM. ${ }^{14}$ This concerned standalone programmes or activities, as well as activities or programmes as part of a bigger (palliative care) intervention. However, if the $\mathrm{ACP}$ components in such a bigger intervention were not clearly described, we excluded the study.

\section{Information sources and search}

The Preferred Reporting Items for Systematic Reviews and Meta-Analyses checklist for reporting systematic reviews was used as the underlying structure of this review. ${ }^{15}$ A systematic search strategy was developed with the aid of a biomedical information specialist of the Erasmus MC medical library. The following electronic databases were used: Embase, MEDLINE, Web of Science, Scopus, CINAHL EBSCO, PsycINFO, Cochrane, PubMed, LILACS, SciELO, ProQuest and Google Scholar. The search was conducted on 26 June 2015. The search terms for the databases can be found in the online supplementary file (S-box1-11).

\section{Study selection}

Duplicates of the retrieved studies were removed. Based on the inclusion and exclusion criteria (box), two reviewers (LJJ and MZ) independently screened titles and abstracts for eligibility.
Box Inclusion and exclusion criteria for the current review

\section{Inclusion criteria:}

1. Original empirical research on the definitions of advance care planning (ACP), the experiences with and attitudes towards ACP of patients and healthcare professionals (HCPs), the barriers and facilitators related to engagement in ACP and the effects of ACP programmes.

2. Research in the field of chronic respiratory disease.

3. Studies must address ACP, defined as:

a. interventions, programmes or activities that the authors label as 'advance care planning' or

b. Studies addressing one or more core elements of ACP as defined by the National Academy of Medicine ${ }^{14}$

1. discussing values and goals for future medical care and treatment with an HCP

2. clarifying values and goals for future medical care and treatment

3. involving a personal representative

4. documenting patients' wishes.

4. Studies published in English.

\section{Exclusion criteria:}

1. Studies in which ACP is only an element of a more complex care programme, such as palliative care, and specific content on ACP are not clearly described.

2. Studies involving children and adolescents.

Thereafter, they reviewed the full text of the remaining studies. Disagreements were discussed, if necessary, including IJK and JACR, and solved. The reviewers used the web-based software platform Covidence (www.covidence.org) for screening and reviewing the studies.

\section{Data extraction}

We developed a data extraction form for this systematic review and used it to extract data on the study characteristics and results of the studies. We extracted the elements of ACP that were described in the conducted studies. Furthermore, we extracted data on the patients' as well as the HCPs' perspective on ACP, organising the results into experiences with and attitudes towards ACP, barriers and facilitators related to engagement in ACP and the effects of ACP programmes. We defined barriers and facilitators as predisposing factors reported by either patients, HCPs or both that hamper or facilitate engagement in ACP. We solely included those barriers and facilitators that were endorsed by at least $10 \%$ of the participants of the particular study. We chose for the cut-off point of $10 \%$ of participants to include as much information as possible, while at the same time keeping the information relevant and meaningful. The extraction was completed by one author (LJJ) and checked by another author (MZ). Disagreements were discussed and solved.

\section{Risk of bias assessment and quality appraisal}

\section{Risk of bias assessment}

The quantitative studies were assessed by two reviewers (LJJ and MZ) with a standardised form of seven items in a modified version of the guidelines for methodological quality assessment of the Dutch Cochrane Centre. ${ }^{16}$ The checklist assesses the (1) research hypothesis, (2) study population, (3) 
selection bias, (4) exposure, (5) outcome, (6) confounding and (7) a general opinion on the study's validity and applicability. A score of 1 was assigned when the criterion had been met sufficiently, a score of 0 when the criterion had not been met sufficiently and a question mark when the information for rating the criterion was lacking. The rating resulted in a total score from 0 to 7 . A score of three or less was considered a study of low quality.

\section{Quality appraisal}

For the quality appraisal of the qualitative studies, two reviewers (LJJ and MZ) used the 'Consolidated criteria for reporting qualitative research' (COREQ) list, ${ }^{17}$ which is recommended by Cochrane Netherlands. The COREQ is a 32 -item checklist, developed to promote explicit and comprehensive reporting of qualitative studies. The checklist evaluates qualitative studies on three domains: (1) research team and reflexivity, (2) study design and (3) analysis and findings. A plus (+) was assigned when the criterion had been properly described (score 1), a minus $(-)$ when it was described unclearly (score 0 ) and a plus-minus $(+/-)$ when the description was incomplete (score 0.5 ). Points were added for a total score ranging from 0 to 32 .

\section{RESULTS}

\section{Study selection}

Our systematic search identified 4031 studies as potentially eligible for this review. After removing duplicates, 2509 studies remained, which were screened based on title and abstract. 2264 studies were excluded, mostly because ACP was only an element of an overarching intervention, such as a palliative care programme, and the ACP-specific components were not clearly described. Full text of 245 studies was assessed for eligibility. In the end, 21 studies were included for the analysis (see figure 1).

\section{Study characteristics}

Of the 21 studies, 10 had a quantitative study design (table 1$).{ }^{18-27}$ Out of these 10 studies, eight were observational, cross-sectional and retrospective. ${ }^{19} 2022-27$ Nine studies had been conducted in the USA. ${ }^{18} 20-2325262829$ Studies involved patients with COPD $(\mathrm{n}=13),{ }^{18} 19{ }^{23-25} 27$ 30-36 chronic lung diseases $(\mathrm{n}=5),{ }^{20-22} 2937$ cystic fibrosis $(n=2)^{2628}$ and progressive idiopathic fibrotic interstitial lung disease $(n=1) .{ }^{38}$ Sixteen studies described the patients' perspective on $\mathrm{ACP}^{18} 21-26 \quad 28-30 \quad 33-38$ and nine described the perspective of HCPs. ${ }^{19} 2024252729313238$ Sixteen studies had been conducted in an outpatient setting. ${ }^{18-26} 29303233$ 35-37 Sample sizes varied from 17 to 513 in the studies with a quantitative design and from 7 to 67 in those with a qualitative design. Five studies evaluated an ACP programme. ${ }^{18} 21333537$ Studies were published between 1996 and 2014.

Online supplementary tables 1 and 2 present the results of the risk of bias assessment of the quantitative studies and the results of the quality appraisal of the qualitative studies, respectively. One study that was described in a 'short communication' was of low quality (score of 2), due to concerns about the rationale of the study, study population and selection bias, as well as potential confounding. ${ }^{27}$ The quality scores of the remaining quantitative studies ranged from 4 to 7 , indicating overall good quality of the studies. One study had the maximum score of $7 .{ }^{24}$ Four studies had a score of 6 . The results of these studies should be interpreted in the light of concerns about confounding ${ }^{182}$ and selection bias. ${ }^{2325}$ These concerns were also the most prominent quality issues of the quantitative studies in general (risk of possible confounding in 6 out of 10 studies, concerns about selection bias in 4 out of 10 studies).

The mean quality appraisal score of the qualitative studies was 16.5 of 32 (range 12-26.5). Almost all studies had poor ratings on the first domain, 'Research team and reflexivity'. Studies with the lowest scores also provided insufficient information on the domains 'Study design' and 'Analysis and finings'. The first domain 'research team and reflexivity' was reported the poorest throughout all studies, which clearly had a detrimental impact on the overall quality of the studies.

\section{Synthesis of results}

Core elements of ACP studied in chronic respiratory disease

Our first aim was to summarise how ACP is defined in chronic respiratory disease. We therefore gathered which elements of ACP were described in the conducted studies (table 2). The vast majority of studies investigated the discussion of end-of-life care in their studies. The documentation of patients' wishes was investigated in about half of the studies.

\section{Experiences with and attitudes towards ACP in chronic respiratory} disease from a patient perspective

Involvement in discussions about end-of-life care preferences was addressed in 11 articles. Six of these studies had a quantitative study design. Seven studies involved patients with COPD. Per study, 12\%-32\% of patients could recall involvement in end-of-life care discussions. ${ }^{18}$ 23-26 The qualitative studies found that patients could rarely recall these discussions. $^{29303436}$

Eight studies addressed patients' interest in discussing end-of-life care preference. Two quantitative studies, each of high quality, involved patients with COPD and chronic lung diseases in an outpatient setting and found that $68 \%$ and $99 \%$ of the patients, respectively, were interested in discussing end-oflife care preferences (online supplementary table 3$).{ }^{18} 22$ In five qualitative studies, patients with a variety of chronic respiratory diseases expressed willingness to discuss end-of-life care preferences. $^{29} 30343638$ Two of these qualitative studies revealed some hesitation of patients to talk about end-of-life care preferences, mainly due to uncertainty about the stability of their preferences and the sensitive nature of the topic. ${ }^{3436}$

Seven studies addressed the documentation of preferences. Two quantitative studies of high quality, in an outpatient setting with patients with chronic lung diseases and cystic fibrosis, found that $30 \%$ and $42 \%$ of patients reported documentation of their wishes through an AD. ${ }^{22}{ }^{26}$ Documentation of patients' wishes however did not always result in those wishes being discussed with the HCP, merely 19\% of the patients in this study discussed their ADs with their HCPs. ${ }^{22}$ In four qualitative studies, involving patients with a variety of chronic respiratory diseases in inpatient as well as outpatient clinics, only a minority of the interviewed patients had heard of an AD. ${ }^{29} 303438$

\section{Experiences with and attitudes towards ACP in chronic respiratory} disease from a HCP perspective

Eight studies addressed the experiences with and attitudes towards ACP from the HCP perspective (online supplementary table 4). Four of these were quantitative studies, in both inpatient as well as outpatient settings, and addressed the engagement of HCPs in ACP discussions. ${ }^{19} 202427$ The percentage of self-reported engagement in ACP was 20\%-33\% in the three highquality studies ${ }^{1920}$ and $13 \%$ in a pilot study of low quality. ${ }^{27}$ 


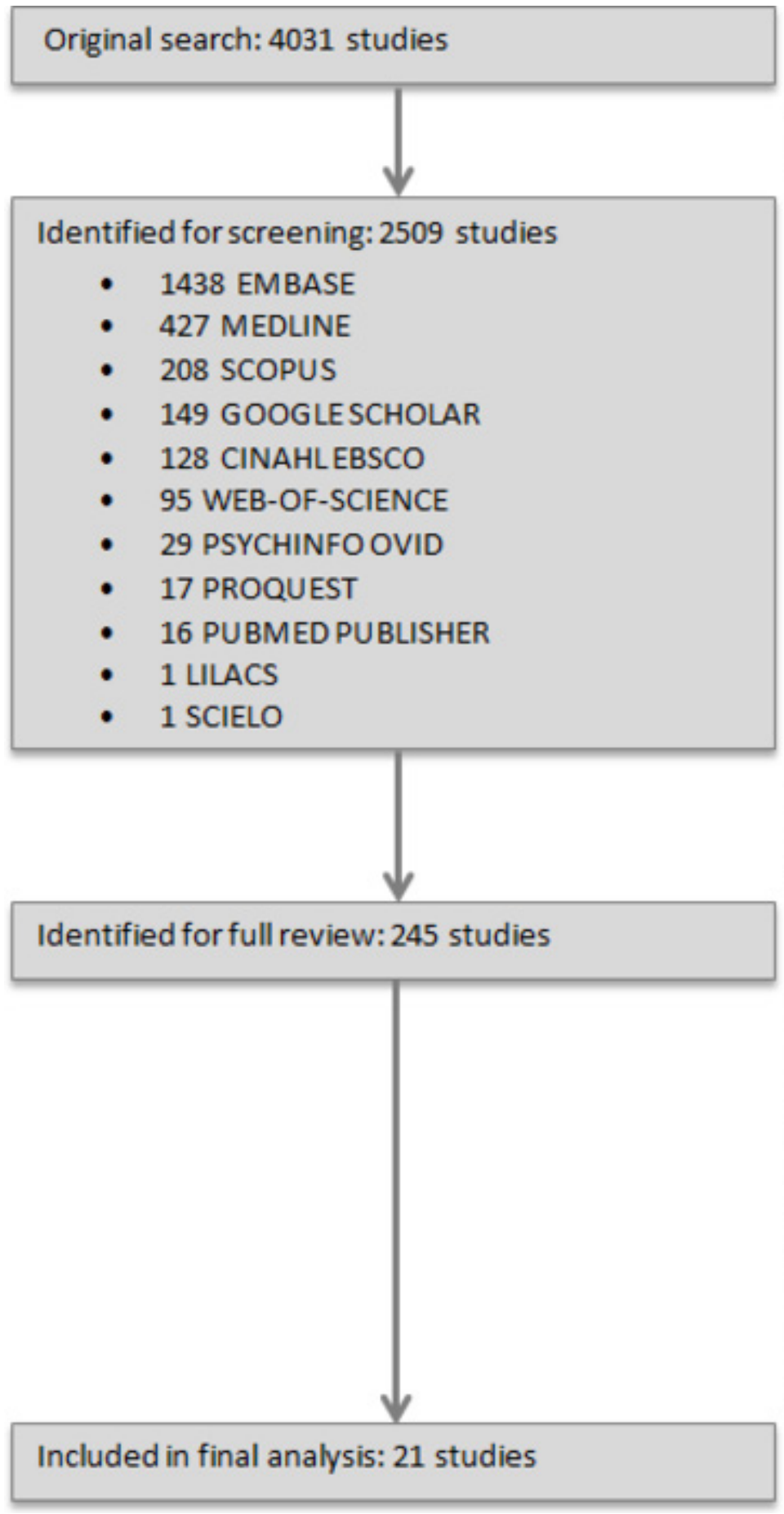

Removal of duplicates led to 1522 exclusions.

Screening of title and abstracts led to 2264

exclusions.

\section{Full review led to 224 exclusions: \\ 66 Not empirical \\ 63 No chronic respiratory dise ases \\ 88 No ACP or ACP only an element of a more complex intervention \\ 5 Not in English \\ 1 Paediatric population \\ 1 Reported on same patient population as included paper}

Figure 1 Flow diagram of article inclusion for this review. ACP, advance care planning.

Two of these high-quality studies and the pilot study of lower quality found that $42 \%-77 \%$ of HCPs recognised the importance of discussing end-of-life care topics. ${ }^{19} 2027$

The vast majority of HCPs in two qualitative studies with patients with COPD and chronic lung diseases in an outpatient setting endorsed the need of discussing end-of-life care. ${ }^{29} 32$ HCPs in one of these studies stated that not discussing end-oflife care would limit patient choice. ${ }^{32}$ The pilot study that was carried out in Australia found that 41\% of HCPs thought that their patients would be willing to discuss their wishes. ${ }^{27}$

The same Australian study found that $77 \%$ of HCPs felt comfortable to talk about end-of-life care, ${ }^{27}$ while a high-quality study from Portugal revealed that $89 \%$ of HCPs found it difficult to engage in discussions on end-of-life care preferences. ${ }^{19}$ Two qualitative studies that involved patients with COPD and progressive idiopathic fibrotic interstitial lung disease (PIF-ILD) in an inpatient clinic showed that HCPs had doubts about the right moment to initiate these discussions on end-of-life care preferences $^{3138}$ and felt uncomfortable to share prognostic estimates such as life expectancy. ${ }^{29}$ In one qualitative study ${ }^{31}$ that involved COPD inpatients, HCPs emphasised that the timing of engaging in these discussions was crucially dependent on the patients' disease pathway and highlighted a clear difference between diseases. ${ }^{31}$ 
Table 1 Study characteristics of the included studies

\begin{tabular}{|c|c|c|c|c|c|}
\hline First author (year) & Study design & Country & Setting & Type of disease & $\begin{array}{l}\text { Sample size } \\
\text { (response rate (\%)) }\end{array}$ \\
\hline \multicolumn{6}{|c|}{ Quantitative study design } \\
\hline \multicolumn{6}{|l|}{ Target group: patients } \\
\hline $\mathrm{Au}(2012)^{18}$ & $\begin{array}{l}\text { Experimental } \\
\text { Longitudinal } \\
\text { Prospective }\end{array}$ & USA & Outpatient clinic & COPD & $306(81)$ \\
\hline Heffner $(1997)^{21}$ & $\begin{array}{l}\text { Experimental } \\
\text { Longitudinal } \\
\text { Prospective }\end{array}$ & USA & Outpatient clinic & Chronic lung diseases & 93 (ns)* \\
\hline Heffner $(1996)^{22}$ & $\begin{array}{l}\text { Observational } \\
\text { Cross-sectional } \\
\text { Retrospective }\end{array}$ & USA & Outpatient clinic & Chronic lung diseases & $105(100)$ \\
\hline Janssen $(2011)^{23} \dagger$ & $\begin{array}{l}\text { Observational } \\
\text { Cross-sectional } \\
\text { Retrospective }\end{array}$ & NL/USA & Outpatient clinic & COPD & 513 (ns) * \\
\hline Sawicki $(2008)^{26}$ & $\begin{array}{l}\text { Observational } \\
\text { Cross-sectional } \\
\text { Retrospective }\end{array}$ & USA & Outpatient clinic & Cystic fibrosis & $234(77)$ \\
\hline \multicolumn{6}{|c|}{ Target group: patients and healthcare professionals } \\
\hline Janssen $(2011)^{24}$ & $\begin{array}{l}\text { Observational } \\
\text { Cross-sectional } \\
\text { Retrospective }\end{array}$ & NL & Outpatient clinic & COPD & $\begin{array}{l}105 \text { patients }(63), \\
101 \text { HCPs }(96)\end{array}$ \\
\hline Knauft $(2005)^{25}$ & $\begin{array}{l}\text { Observational } \\
\text { Cross-sectional } \\
\text { Retrospective }\end{array}$ & USA & Outpatient clinic & COPD & $\begin{array}{l}115 \text { patients }(40), \\
56 \text { HCPs }(86)\end{array}$ \\
\hline \multicolumn{6}{|c|}{ Target group: healthcare professionals } \\
\hline Gaspar $(2014)^{19}$ & $\begin{array}{l}\text { Observational } \\
\text { Cross-sectional } \\
\text { Retrospective }\end{array}$ & Portugal & Inpatient and outpatient clinic & COPD & $136(29)$ \\
\hline Heffner $(1996)^{20}$ & $\begin{array}{l}\text { Observational } \\
\text { Cross-sectional } \\
\text { Retrospective }\end{array}$ & USA & Outpatient clinic & Chronic lung diseases & $218(63)$ \\
\hline Smith $(2014)^{27}$ & $\begin{array}{l}\text { Observational } \\
\text { Cross-sectional } \\
\text { Retrospective }\end{array}$ & Australia & Inpatient clinic & COPD & $17(41)$ \\
\hline \multicolumn{6}{|l|}{ Qualitative study design } \\
\hline \multicolumn{6}{|l|}{ Target group: patients } \\
\hline Brown $(2012)^{30}$ & Semistructured interviews & Australia & Outpatient clinic & COPD & 15 \\
\hline Dellon $(2010)^{28}$ & Semistructured interviews & USA & Inpatient clinic & Cystic fibrosis & 36 \\
\hline MacPherson $(2013)^{36}$ & Semistructured interviews & UK & $\begin{array}{l}\text { Inpatient clinic, } \\
\text { GP practices }\end{array}$ & COPD & 10 \\
\hline Seamark $(2012)^{34}$ & Semistructured interviews & UK & Inpatient clinic & COPD & 16 \\
\hline Simpson $(2011)^{35}$ & Semistructured interviews & Canada & Outpatient clinic & COPD & 8 \\
\hline Nguyen $(2013)^{33}$ & Qualitative descriptive & Canada & Outpatient clinic & COPD & 12 \\
\hline Burge $(2013)^{37}$ & $\begin{array}{l}\text { Prospective semistructured } \\
\text { interviews }\end{array}$ & Australia & Inpatient and outpatient clinic & Chronic lung diseases & 67 \\
\hline \multicolumn{6}{|c|}{ Target group: patients and healthcare professionals } \\
\hline Bajwah $(2013)^{38}$ & Semistructured interviews & UK & Inpatient clinic & PIF-ILD & $\begin{array}{l}8 \text { patients } \\
6 \text { HCPs }\end{array}$ \\
\hline Hajizadeh $(2015)^{29}$ & Semistructured interviews & USA & Outpatient clinic & Chronic lung diseases & $\begin{array}{l}11 \text { patients } \\
\text { five physicians }\end{array}$ \\
\hline \multicolumn{6}{|c|}{ Target group: healthcare professionals } \\
\hline Crawford $(2010)^{31}$ & Semistructured interviews & UK & Inpatient clinic & COPD & 7 \\
\hline Gott $(2009)^{32}$ & Focus group & UK & GP practices & COPD & 39 \\
\hline
\end{tabular}

${ }^{*}$ ns=response rate not specified.

tData of a part of the included patients in this study were also used in the analysis of the study by Jansen et al. ${ }^{24}$

COPD, chronic obstructive pulmonary disease; GP, general practitioner; PIF-ILD, progressive idiopathic fibrotic interstitial lung disease; NL, the Netherlands. 
Table 2 Core elements of advance care planning studied in chronic respiratory disease $(n=21)$

Specific core elements of advance care planning as addressed in studies in chronic respiratory disease $(n=21)$

Core elements of advance care planning

(1) Discussing end-of-life care

$20^{18-3638}$

(2) Clarifying values and goals

$7^{18192324272933}$

(3) Involving a personal representative

(4) Documenting patients' wishes

$11^{19-22} 26293033-36$

\section{Barriers and facilitators related to patient and HCPs' engagement in ACP}

Table 3 shows the most frequently described barriers and facilitators related to patient and HCPs' engagement in ACP. $^{19} 21232527-343738$ The barriers and facilitators described in these 13 studies were related to the level of the patient, the HCP and the healthcare system.

Two high-quality quantitative studies and three qualitative studies, involving patients with COPD and PIF-ILD, and their HCPs described insufficient awareness of patients about the nature of their disease, especially about its severity, as a barrier to ACP. ${ }^{2325293238}$ Four studies, among which one high-quality quantitative study, found that the unpredictable disease course of these diseases, particularly COPD, makes it difficult for HCPs to define and communicate the prognostic estimates to patients. ${ }^{19273132}$ The same four studies and an additional highquality quantitative study found that the complex disease course of chronic respiratory diseases also makes it difficult for HCPs to identify trigger points for the initiation of ACP, especially in chronic lung diseases. ${ }^{1925273132}$ Besides, HCPs perceive patients to be hesitant to consider and discuss end-of-life care, ${ }^{19} 2527$ while patients perceived HCPs to be reluctant to initiate ACP discussions. ${ }^{21}{ }^{23}$ This impression by patients aligns with HCPs acknowledging their fear of taking away patients' hope. This might be related to an ethos of 'cure at all costs', as identified by three studies in the UK, USA and Portugal involving patients with COPD. ${ }^{19} 2532$

Seven studies reported system-related barriers to ACP, among which time constraints, 33252729323438 a lack of structural support, such as a lack of continuity of care, ${ }^{21} 2325303238$ and a lack of formal training in communicating end-of-life care options. ${ }^{1922323738}$ Two quantitative and two qualitative studies found that both patients and HCPs perceived lack of continuity and coordination of care as a barrier, ${ }^{23} 253038$ resulting in uncertainty about whose responsibility it is to initiate ACP discussions and to follow-up on these discussions. ${ }^{21} 32$

Two qualitative studies, involving patients with COPD and cystic fibrosis, identified patient knowledge and understanding of the nature of their disease as a facilitator for engagement in $\mathrm{ACP}^{28} 33$ Patients' acceptance of their disease was mentioned as another facilitator. ${ }^{27} 3133$ Three studies with patients with COPD and cystic fibrosis found that patient acceptance might increase with disease progression. ${ }^{23} 2528$ Two high-quality quantitative studies suggested that with disease progression, patients' worries about becoming a burden for loved ones increased, which in turn was found to be a facilitator for engagement in ACP. ${ }^{23} 25$ Engagement in ACP was more acceptable to patients who previously experienced loved ones having to decide about end-of-life care or who had experienced loved ones dying. ${ }^{23} 2533$

Three quantitative studies, among which two of high quality and one qualitative study, found that patients as well as HCPs perceived talking about ACP to be easier when patients had an advanced disease stage. ${ }^{23252729}$ The identification of the right moment and setting to engage in ACP discussions was perceived as beneficial by both, ${ }^{28} 3132$ as well as the HCPs' expertise in caring for patients with lung disease or end-of-life care. ${ }^{23} 2534$ While patients with COPD and cystic fibrosis preferred ACP discussions to be initiated by HCPs, ${ }^{23} 2528$ one qualitative study with patients with COPD in the UK found that HCPs preferred patients to start discussions on end-of-life care. ${ }^{31}$ The implementation of trigger points to discuss ACP, such as the start of oxygen therapy, could help to overcome this dilemma. ${ }^{32}$ Patients and HCPs experienced a good patient-HCP relationship, characterised by trust and continuity, as supportive for engagement in $\mathrm{ACP}^{23} 25313334$

\section{Effects of ACP programmes}

Five studies, two quantitative and three qualitative, evaluated the effects of an ACP programme (online supplementary table $5) .{ }^{18} 21333537$ Two high-quality quantitative studies evaluated a patient-specific feedback form to stimulate ACP conversations in

Table 3 Barriers and facilitators related to engagement in ACP

\begin{tabular}{|c|c|c|c|}
\hline \multicolumn{2}{|c|}{ Patient related } & \multirow{2}{*}{$\begin{array}{l}\text { HCP related } \\
\text { Perceived hesitance of HCPs to discuss } \\
\text { preferences and engage in } \mathrm{ACP} .^{21}{ }^{23}\end{array}$} & \multirow{2}{*}{$\begin{array}{l}\text { System related } \\
\text { Ethos of 'cure at all costs' in. }{ }^{32}\end{array}$} \\
\hline Barriers & $\begin{array}{l}\text { Insufficient patient knowledge about their own } \\
\text { disease. }^{2325293238}\end{array}$ & & \\
\hline & $\begin{array}{l}\text { Unpredictable disease course and difficult } \\
\text { prognostication. }{ }^{1925273132}\end{array}$ & $\begin{array}{l}\text { HCP's perceived fear of taking away patients' } \\
\text { hope. }^{1925}\end{array}$ & Perceived HCP's time constraints. ${ }^{23272932343538}$ \\
\hline & \multirow[t]{2}{*}{$\begin{array}{l}\text { Perceived patient hesitation for considering and } \\
\text { discussing treatment preferences. }{ }^{192527}\end{array}$} & & $\begin{array}{l}\text { Lack of organisational support and formal training on } \\
\text { communicating end-of-life care options. }{ }^{1922323738}\end{array}$ \\
\hline & & & $\begin{array}{l}\text { Lack of continuity and coordination of care including } \\
\text { uncertainty on whose responsibility it is to initiate and } \\
\text { follow-up on ACP discussions. }{ }^{212529303238}\end{array}$ \\
\hline \multirow[t]{4}{*}{ Facilitators } & $\begin{array}{l}\text { Increased patient knowledge on terminal nature of } \\
\text { their disease. }\end{array}$ & Advanced stage of disease. 23252729 & $\begin{array}{l}\text { Patient initiation of ACP (as experienced by HCPs) }{ }_{2}^{31} \mathrm{HCP} \\
\text { initiation of ACP (as experienced by patients). }{ }_{2328}^{25}\end{array}$ \\
\hline & $\begin{array}{l}\text { Patients accepting their disease, increasing readiness } \\
\text { to discuss end-of-life care. }{ }^{273133}\end{array}$ & $\begin{array}{l}\text { Identification of the right moment and setting } \\
\text { to engage in an ACP discussion. }{ }^{283132}\end{array}$ & Implementation of trigger points to discuss $\mathrm{ACP} .^{32}$ \\
\hline & Patient worry to become a burden for the family. ${ }^{2325}$ & $\begin{array}{l}\text { HCPs' experience with care for patients at the } \\
\text { end of life/ with lung diseases. }{ }^{232534}\end{array}$ & $\begin{array}{l}\text { Continuity of care, including good HCP-patient } \\
\text { relationship. } 2325313334\end{array}$ \\
\hline & Patient experience with end of life. ${ }^{233335}$ & & \\
\hline
\end{tabular}

Patient experience with end of life..$^{23} 3335$ 
patients with $\mathrm{COPD}^{18}$ and educational workshops on $\mathrm{ADs}$ and other end-of-life topics for patients with chronic lung diseases. ${ }^{21}$ The interventions increased quality of end-of-life care communication ${ }^{18}$ and resulted in an increased number of completed living wills. $^{21}$

The three qualitative studies evaluated programmes ranging from delivering video material to patients with $\mathrm{COPD}^{33}$ to ACP conversations based on a conversation guide for patients with chronic lung diseases and COPD. ${ }^{35} 37$ Some patients perceived the information presented as confrontational, nevertheless they agreed about the need to gain a thorough understanding of treatment options. ${ }^{33} 3537$ Considering the timing of the discussions, a study on the effects of a DVD movie covering information on end-of-life care options found that most patients wished their HCPs to mainly be sensitive to their individual needs. ${ }^{33}$

\section{DISCUSSION}

This is the first systematic review thoroughly describing ACP practice in chronic respiratory disease, summarising findings on how ACP is defined in chronic respiratory disease, the experiences with and attitudes towards ACP of patients and HCPs, the barriers and facilitators related to engagement in ACP and the effects of ACP programmes. We summarised the findings of 21 studies. Only five of these studies, which mostly had a qualitative study design, evaluated an ACP programme, suggesting that ACP programmes are less commonly studied in chronic respiratory disease than in other disease groups such as motor neuron disease and with nursing home residents. ${ }^{39} 40$ By looking at the definitions of ACP in chronic respiratory disease and the elements being investigated in the 21 studies themselves, we found that only 10 studies provided an explicit operationalisation of ACP. The remaining studies did not mention the term ACP at all. This suggests that the concept of ACP is not widely known or used in chronic respiratory disease.

The assessment of the elements of ACP described in the conducted studies revealed that in contrast to the NAM definition most of the studies did not include the clarification of patients' values and goals in their studies. According to the American Thoracic Society, comprehensive ACP however is a holistic approach, tailored to individual needs. Solely discussing treatment options without grounding these in the discussion about patients' values and goals lowers the chance that patient-centred treatment decisions are made. ${ }^{8}$ We also found that the descriptions of ACP only rarely included the involvement of a personal representative in ACP. While traditionally ACP focused mainly on the completion of written documents, the American Thoracic Society ${ }^{8}$ nowadays acknowledges the importance of patient-centred conversations about treatment decisions as well as the involvement of a personal representative. Involving family caregivers can ensure that patient preferences will still be taken into account, even if patients lose their decision-making capacity. ${ }^{8}$

ACP is widely embraced by professional bodies such as the British Thoracic Society, American Thoracic Society and the American College of Chest Physicians. ${ }^{8} 1112$ Cumulative evidence, predominantly from studies in other disease groups, has established the positive effect of communication between patients and HCPs on patients' quality of life. ${ }^{13}$ Our systematic review shows that many patients with chronic respiratory diseases and their HCPs are interested in engaging in ACP, while less patients reported to have had such conversations. The low uptake of these discussions seems to be comparable with other disease groups: $20 \%$ of general medicine patients and
$29 \%$ of hospitalised cancer patients reported having had ACP discussions. ${ }^{41}{ }^{42}$ Apparently, there is a discrepancy between the expressed interest in ACP discussions and the extent to which ACP discussions take place. Our systematic review suggests three main explanations for this phenomenon.

First of all, chronic respiratory diseases are often characterised by a complex and unpredictable disease course. ${ }^{45}$ Murray $e t ~ a l^{6}$ describe the illness trajectory of lung failure as long-term limitations with intermittent serious episodes. Patients with chronic respiratory diseases are usually ill for a longer period of time, interrupted by occasional acute and often severe exacerbations. As a result, it is difficult for HCPs to provide the patient with prognostic estimates,${ }^{6}$ hence complicating the choice of timing and content of ACP discussions.

Stapleton and Curtis ${ }^{1}$ advise to engage in ACP in any case earlier than it is usually done. They advise to start when patients are still relatively well and able to participate in decision making ${ }^{8}$ to prevent that the impact of their decisions on their (end-oflife) care is limited. ${ }^{43}$ This advice might be of particular importance for patients with COPD, since Lau et al ${ }^{44}$ found $26.9 \%$ of patients having their first ACP discussions only 3 days before death. While indeed ACP discussions can start any time, they can become more targeted as the patient's health condition worsens. ${ }^{45}$ To support HCPs in finding a good moment for ACP discussions, Bernacki and Block ${ }^{43}$ made an effort to identify trigger points for starting ACP discussions. Examples of such trigger points are ongoing oxygen requirement of patients with COPD or lack of further treatment options. A negative response on the 'surprise question' ('Would you be surprised if this patient died in the next year?') could serve as an indication for HCPs to initiate ACP, ${ }^{43}$ although further validation of this question is necessary in this population. Another way of enabling ACP discussions is to remain alert for patient-induced triggers. Patients reported that experiences with death and dying of family and friends facilitated their thinking about end-of-life care. Responding to and elaborating these experiences can help to initiate ACP discussions.

The second explanation for the low frequency of ACP in chronic respiratory disease is that despite of HCPs recognising the importance of engaging in ACP, they often fear taking away patients' hope. Related to this, HCPs also reported a lack of training on communicating sensitive topics such as end-of-life care options without threatening the patients' emotional wellbeing and feelings of hope. However, a qualitative study on the perspectives of nurses on meeting patients' needs for hope and illness information ${ }^{46}$ and a review on hope in palliative care found that honest information about the patient's illness can contribute to patient hope. ${ }^{47}$ Patients were, for example, hoping to live to the fullest in the time they have left. ${ }^{47}$ In fact, being able to talk about death and dying gave patients a sense of control and made them less afraid of the process of decision making. ${ }^{47}$ Our review also found that patients do not feel well informed and educated about their disease, and HCPs confirmed that patients lack knowledge particularly about the severity of their disease. Patients seem to appreciate information about their disease, if sensitively introduced. This also highlights the importance of good communication skills and training for HCPs. Providing information on the disease, possible disease course and treatment options can be the first step of ACP.

The third explanation for the low frequency of ACP discussions in chronic respiratory disease is that system-related barriers such as time constraints and lack of continuity of care limit the opportunity for both patients and HCPs to engage in ACP during medical encounters. Patients' care trajectory is often characterised 
by profound breaks in care settings and HCPs. These breaks in care make it a complex task for HCPs to assess patients' level of awareness and readiness to engage in ACP. Continuity of care can be strengthened by documenting discussions on diagnosis, prognosis, treatment and care options in the medical file. A reliable system for storing written advance care documents can ensure that these documents can be retrieved and transferred easily. Besides, it can be valuable to look for settings in which patients with chronic respiratory diseases are treated throughout their disease trajectory, such as pulmonary rehabilitation. ${ }^{21}{ }^{22}$ Due to their long-term relationship with the patient, general practitioners might be in a good position to be involved in ACP as well. ${ }^{48}$

\section{Limitations}

This review however has some limitations. First, we aimed at a comprehensive search strategy by searching in 12 electronic databases and also including studies that addressed the core elements of ACP without explicitly mentioning the term 'advance care planning'. However, if ACP was part of a larger palliative care programme and it was not possible to answer our research questions regarding specific ACP elements of the programme, we had to exclude the respective paper. This may have affected our results to some extent. Second, since the studies were mainly descriptive, statements of causality cannot be made. Finally, our search was limited to published articles in English language, which creates the possibility of publication bias.

\section{CONCLUSION}

This systematic review, summarising findings of 21 studies, provides, for the first time, an in-depth picture of ACP practice in chronic respiratory disease, summarising findings on how ACP is defined in chronic respiratory disease, the experiences with and attitudes towards ACP of patients and HCPs, the barriers and facilitators related to engagement in ACP and the effects of ACP programmes. ACP seems to be acceptable and desired, by both patients and HCPs, while the occurrence of ACP appears to be low. The complex disease course of chronic respiratory diseases and hesitance of both patients and HCPs to engage in ACP as well as system-related factors create barriers to engagement in ACP. These barriers could be overcome by, first, identifying trigger points throughout the disease course to discuss ACP, and second, training HCPs on how to communicate sensitive topics such as end-of-life care. Finally, making system-related adjustments, such as enabling continuity of care, allowing the initiation of ACP in appropriate healthcare settings and taking away time pressure from HCPs can help to take away barriers preventing engagement in ACP.

Correction notice This article has been corrected since it was published Online First. The following information has now been included. Judith A C Rietjens and Ida J Korfage shared last authorship, based on equal contribution to the manuscript.

Twitter Follow Lea J Jabbarian @JabbarianL and @ACPinscience

Acknowledgements The authors would like to thank Wichor Bramer for his help with the development of the search strategy in the electronic literature databases.

Contributors LJ and MZ screened and accessed the data. All authors made substantial contributions to the interpretation of the data. LJ wrote the paper. MZ, AvdH, MK, DJAJ, JJvD, JACR and IJK critically revised the manuscript for important intellectual content. All authors approved the final version to be submitted for publication.

Funding This systematic review is part of a larger study about advance care planning in oncology: the ACTION study. The ACTION study (Advance care planning - an innovative palliative care intervention to improve quality of life in oncology) is a collaboration between research teams in the Netherlands, Denmark, Belgium, Slovenia, the UK and Italy. The 7th Framework Programme for Research and
Technological Development (FP7) from the European Commission is funding the study (Proposal No: 602541-2)

Provenance and peer review Not commissioned; externally peer reviewed.

(c) Article author(s) (or their employer(s) unless otherwise stated in the text of the article) 2018. All rights reserved. No commercial use is permitted unless otherwise expressly granted.

\section{REFERENCES}

1 Stapleton RD, Curtis JR. End-of-life considerations in older patients who have lung disease. Clin Chest Med 2007:28:801-11.

2 Forum of International Respiratory Societies. Respiratory diesease in the world: Realities of Today - Opportunities for Tomorrow. Sheffield: European Respiratory Society, 2013. https://www.ersnet.org/pdf/publications/firs-world-report.pdf

3 Bousquet J, Khaltaev NG. eds. Global surveillance, prevention and control of chronic respiratory diseases, a comprehensive approach. Switzerland: World Health Organization, 2007. http://www.who.int/gard/publications/GARD\%20Book\%202007. pdf

4 Hardin KA, Meyers F, Louie S. Integrating palliative care in severe chronic obstructive lung disease. COPD 2008;5:207-20.

5 Ketchell RI, Roughton M, Agent $\mathrm{P}$, et al. Predicting survival in end-stage cystic fibrosis. Respir Med 2009;103:1441-7.

6 Murray SA, Kendall M, Boyd K, et al. Illness trajectories and palliative care. BMJ 2005;330:1007-11.

7 Yang IA, Dabscheck E, George J, et al. The COPD-X Plan: Australian and New Zealand Guidelines for the management of Chronic Obstructive Pulmonary Disease 2017. Version 2.50. Jun 2017.

8 American Thoracic Society and European Respiratory Society. Standards for the diagnosis and management of patients with COPD. 2004.

9 Janssen DJA, Spruit MA, Schols J, et al. Predicting changes in preferences for lifesustaining treatment among patients with advanced chronic organ failure. Chest 2012;141:1251-9.

10 Momen N, Hadfield P, Kuhn I, et al. Discussing an uncertain future: end-of-life care conversations in chronic obstructive pulmonary disease. A systematic literature review and narrative synthesis. Thorax 2012;67:777-80.

11 Selecky PA, Eliasson CA, Hall RI, et al. Palliative and end-of-life care for patients with cardiopulmonary diseases: American College of Chest Physicians position statement. Chest 2005;128:3599-610.

12 Davidson C, Banham S, Elliott M, et al. British Thoracic Society/Intensive Care Society Guideline for the ventilatory management of acute hypercapnic respiratory failure in adults. BMJ Open Respir Res 2016;3:e000133.

13 Brinkman-Stoppelenburg A, Rietjens JA, van der Heide A. The effects of advance care planning on end-of-life care: a systematic review. Palliat Med 2014;28:1000-25.

14 IOM (Institute of Medicine). Dying in America: Improving quality and honoring individual preferences near the end of life. Washington, DC: The National Academies Press, 2015.

15 Liberati A, Altman DG, Tetzlaff J, et al. The PRISMA statement for reporting systematic reviews and meta-analyses of studies that evaluate healthcare interventions: explanation and elaboration. BMJ 2009:339:b2700.

16 Dutch Cochrane Centre. Guideline for methodological quality assessment of observational studies [in Dutch]. Dutch Cochrane Centre, 2010. www.cochrane.nl/ downloads

17 Tong A, Sainsbury P, Craig J. Consolidated criteria for reporting qualitative research (COREQ): a 32-item checklist for interviews and focus groups. Int I Qual Health Care 2007:19:349-57.

$18 \mathrm{Au}$ DH, Udris EM, Engelberg RA, et al. A randomized trial to improve communication about end-of-life care among patients with COPD. Chest 2012:141:726-35.

19 Gaspar C, Alfarroba S, Telo L, et al. End-of-life care in COPD: a survey carried out with Portuguese pulmonologists. Rev Port Pneumol 2014;20:123-30.

20 Heffner JE, Fahy B, Barbieri C. Advance directive education during pulmonary rehabilitation. Chest 1996;109:373-9.

21 Heffner JE, Fahy B, Hilling L, et al. Outcomes of advance directive education of pulmonary rehabilitation patients. Am J Respir Crit Care Med 1997;155:1055-9.

22 Heffner JE, Fahy B, Hilling $L$, et al. Attitudes regarding advance directives among patients in pulmonary rehabilitation. Am J Respir Crit Care Med 1996:154:1735-40.

23 Janssen DJ, Curtis JR, Au DH, et al. Patient-clinician communication about end-of-life care for Dutch and US patients with COPD. Eur Respir J 2011;38:268-76.

24 Janssen DJA, Spruit MA, Schols J, et al. A call for high-quality advance care planning in outpatients with severe COPD or chronic heart failure. Chest 2011;139:1081-8.

25 Knauft E, Nielsen EL, Engelberg RA, et al. Barriers and facilitators to end-of-life care communication for patients with COPD. Chest 2005;127:2188-96.

26 Sawicki GS, Dill EJ, Asher D, et al. Advance care planning in adults with cystic fibrosis. J Palliat Med 2008;11:1135-41.

27 Smith TA, Kim M, Piza M, et al. Specialist respiratory physicians' attitudes to and practice of advance care planning in COPD. a pilot study. Respir Med 2014;108:935-9. 
28 Dellon EP, Shores MD, Nelson Kl, et al. Caregiver perspectives on discussions about the use of intensive treatments in cystic fibrosis. J Pain Symptom Manage 2010;40:821-8.

29 Hajizadeh N, Uhler LM, Pérez Figueroa RE. Understanding patients' and doctors' attitudes about shared decision making for advance care planning. Health Expect 2015;18:2054-65.

30 Brown M, Brooksbank MA, Burgess TA, et al. The experience of patients with advanced chronic obstructive pulmonary disease and advance care-planning: A South Australian perspective. J Law Med 2012;20:400-9.

31 Crawford A. Respiratory practitioners' experience of end-of-life discussions in COPD. Br J Nurs 2010;19:1164-9.

32 Gott M, Gardiner C, Small N, et al. Barriers to advance care planning in chronic obstructive pulmonary disease. Palliat Med 2009;23:642-8.

33 Nguyen M, Chamber-Evans J, Joubert A, et al. Exploring the advance care planning needs of moderately to severely ill people with COPD. Int J Palliat Nurs 2013;19:389-95.

34 Seamark D, Blake S, Seamark C, et al.Is hospitalisation for COPD an opportunity for advance care planning? A qualitative study. Prim Care Respir J 2012;21:261-6.

35 Simpson AC. An opportunity to care? Preliminary insights from a qualitative study on advance care planning in advanced COPD. Prog Palliat Care 2011;19:243-53.

36 MacPherson A, Walshe C, O'Donnell V, et al. The views of patients with severe chronic obstructive pulmonary disease on advance care planning: a qualitative study. Palliat Med 2013;27:265-72.

37 Burge AT, Lee A, Nicholes M, et al. Advance care planning education in pulmonary rehabilitation: a qualitative study exploring participant perspectives. Palliat Med 2013;27:508-15.

38 Bajwah S, Koffman J, Higginson IJ, et al. 'I wish I knew more ' the end-of-life planning and information needs for end-stage fibrotic interstitial lung disease: views of patients, carers and health professionals. BMJ Support Palliat Care 2013;3:84-90.

39 Martin RS, Hayes B, Gregorevic K, et al. The Effects of Advance Care Planning Interventions on Nursing Home Residents: A Systematic Review. J Am Med Dir Assoc 2016;17:284-93

40 Murray L, Butow PN. Advance care planning in motor neuron disease: A systematic review. Palliat Support Care 2016;14:411-32.

41 Curtis JR, Engelberg RA, Nielsen EL, et al. Patient-physician communication about end-of-life care for patients with severe COPD. Eur Respir J 2004;24:200-5.

42 Schickedanz AD, Schillinger D, Landefeld CS, et al. A clinical framework for improving the advance care planning process: start with patients' self-identified barriers. J Am Geriatr Soc 2009;57:31-9.

43 Bernacki RE, Block SD. American College of Physicians High Value Care Task F. Communication about serious illness care goals: a review and synthesis of best practices. JAMA Intern Med 2014;174:1994-2003.

44 Lau KS, Tse DM, Tsan Chen TW, et al. Comparing noncancer and cancer deaths in Hong Kong: a retrospective review. J Pain Symptom Manage 2010;40:704-14.

45 Butler M, Ratner E, McCreedy E, et al. Decision aids for advance care planning: an overview of the state of the science. Ann Intern Med 2014;161:408-18.

46 Reinke LF, Shannon SE, Engelberg RA, et al. Supporting hope and prognostic information: nurses' perspectives on their role when patients have life-limiting prognoses. J Pain Symptom Manage 2010;39:982-92.

47 Kylmä J, Duggleby W, Cooper D, et al. Hope in palliative care: an integrative review. Palliat Support Care 2009;7:365-77.

48 Michiels E, Deschepper R, Van Der Kelen G, et al. The role of general practitioners in continuity of care at the end of life: a qualitative study of terminally ill patients and their next of kin. Palliat Med 2007:21:409-15. 